\title{
Subdural block: a possible cause of transient aphasia following spinal anaesthesia
}

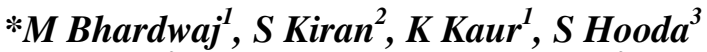 \\ Assistant Professor ${ }^{1}$, Senior Professor ${ }^{2}$, Senior Professor and Head ${ }^{3}$, Department of Anaesthesia and \\ Critical care, Pt. BDS University of Health Sciences, Rohtak, India.
}

*Corresponding author: drbmamta@gmail.com

\begin{abstract}
Central neuraxial blockade is a commonly performed anaesthetic technique for lower limb orthopaedic surgeries. Although it is considered a safe and reliable technique, occasionally an unexpectedly high or low level of block can be achieved due to accidental injection of local anaesthetic in a meningeal plane other than that desired. Here we report a young male who complained of aphasia and difficulty in breathing immediately after spinal anaesthesia. He had a high sensory block extending to C3 dermatome. His haemodynamics remained stable throughout the surgery. Speech returned to normal in 15 minutes. Subdural block was speculated as a cause for this unusual presentation.
\end{abstract}

Keywords: subdural block, aphasia, spinal anaesthesia

\section{Case Report}

Central neuraxial blockade is a common anaesthetic technique for lower limb orthopaedic surgeries. Although it is considered a safe and reliable technique, occasionally an unexpectedly high or low level of block occurs due to accidental injection of local anaesthetic in a meningeal plane other than that desired. ${ }^{1}$ Even cardiac arrests have been reported despite stable haemodynamics. ${ }^{2}$ A greater awareness about variable presentations is important as timely management is essential to avoid critical complications. We hereby report a case that developed aphasia with unexpectedly high sensory level immediately following spinal anaesthesia.

A 19 year old male weighing $65 \mathrm{~kg}$, with a height of $167 \mathrm{~cm}$ belonging to ASA physical status 1 came to emergency operation theatre for interlocking nail for fracture shaft of right femur. His general physical status and all haematological investigations were unremarkable.

In the operation theatre, routine monitors were attached and his vital signs recorded. Peripheral venous line was established with $18 \mathrm{G}$ cannula on right forearm and Ringer's lactate infusion was started. Under aseptic precautions subarachnoid block was given with 23G Quinke's needle in L3/4 space in midline in sitting position in a single atraumatic attempt. Hyperbaric bupivacaine
(0.5\%) $2.8 \mathrm{ml}$ was injected after obtaining clear free flow of cerebrospinal fluid. As the patient was placed in supine position, he became restless and was unable to speak. Immediately $100 \%$ oxygen was administered. His spontaneous respiratory efforts were apparently normal. His heart rate was $86 / \mathrm{min}$, regular, blood pressure was $128 / 64 \mathrm{mmHg}$ and oxygen saturation (SpO2) $98 \%$. Within few seconds, he started sweating with irregular breathing. His breathing was assisted manually with few breaths with a Bain's circuit. He communicated only by moving his head. Level of the spinal block was assessed quickly and it was C3. After five to seven minutes, he started feeling comfortable, sweating decreased and was able to speak in a weak voice. His speech reverted to normal voice in fifteen- twenty minutes. After 20 minutes, sensory level of block had receded to T4. At this time, surgery was commenced and it went on uneventfully for 90 minutes. His haemodynamic parameters were within normal range throughout the surgery. At the time of skin closure, he started complaining of pain at surgical

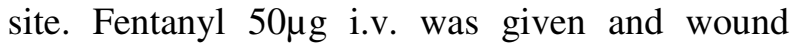
infiltrated with $1 \%$ xylocaine. The incident was not followed by any neurological deficit or post spinal headache. His further stay in hospital was uneventful. 


\section{Discussion}

Spinal anaesthesia conducted under standard conditions carries a poorly understood risk of sudden cardiac arrest and severe brain injury in healthy patients. ${ }^{2}$ The problems encountered in this patient were a very high sensory block with transient aphasia, motor weakness of the upper limbs and difficulty in breathing. Symptoms suggestive of high sub-arachnoid block such as hypotension, bradycardia or pupillary dilatation were not observed.

Excessive sensory blockade with sparing of sympathetic functions is the most common presentation of sub-dural block. Motor weakness is slow to develop and less profound, with progressive respiratory incoordination rather than sudden apnoea. ${ }^{1}$ Many other features of subdural block have been reported in literature such as failed spinal anaesthesia, significant motor weakness of the upper extremities and intercostal muscles, delayed or faster than usual onset of block, significant hypotension and Horner's syndrome. This is due to the anatomy of the subdural space. A study of the ultrastructure of the subdural space using electron microscopy has been helpful in explaining the wide inter patient variability seen with subdural blocks. ${ }^{1}$

The subdural space is a potential cavity containing a small amount of serous fluid between the dura and arachnoid mater. Unlike the epidural space, this space extends from the lower border of the second sacral vertebra into the cranial cavity. ${ }^{3,4}$ It has no communication with the subarachnoid space but is continued on cranial and spinal nerves for a short distance. The dura and arachnoid are attached together on the ventral root, making the space very small ventrally. This causes pooling of drug in dorsal segment and relative sparing of the ventral nerve roots which carry sympathetic and motor fibres. The true incidence of subdural block in routine practice may not be known because a definitive diagnosis depends on computed tomography imaging, which is often not feasible.

Our patient complained of difficulty in breathing, but it never progressed to apnoea. Patchy involvement of the respiratory muscles with sparing of diaphragmatic breathing was sufficient to maintain the $\mathrm{SpO}_{2}$. Loss of consciousness with remarkable haemodynamic stability has been reported in parturients after spinal anaesthesia for caesarean section. ${ }^{5}$ Subdural extension was speculated to be the cause for the unusual presentation. Since the subdural space extends cranially, local anaesthetic block of the brainstem is possible causing loss of consciousness and apnoea. ${ }^{6,7}$ Transient aphasia in our patient could be explained due to the effect of bupivacaine on the brain stem cranial nerves. Although it is difficult to prove or disprove subdural injection in this case, the progression of events can be explained on the basis of subdural injection of local anaesthetic. Subdural catheterization leading to trigeminal nerve palsy has also been reported signifying cephalic spread of local anaesthetic agent into the cranial cavity. Compression of thecal sac, spinal canal abnormalities and difficulties with block placement are risk factors for total spinal anaesthesia and accidental subdural injection. Accidental subdural block has been reported with the use of reusable long bevelled needle and multiple attempts at subarachnoid block. ${ }^{8,9}$ In this case subdural block occurred with a disposable needle and with a single attempt. During the insertion of spinal needle into the subarachnoid space, the bevel may lie partly within both the subdural and subarachnoid spaces. This probability of a needle tip lying within both spaces is more with long bevelled needles. The free flow of CSF at the time of aspiration led to false belief that needle tip was fully in subarachnoid space. On the basis of clinical picture in our case, we speculate that the local anaesthetic was injected into the subarachnoid as well as subdural space and subdural extension was the most likely cause of the clinical presentation. This report is intended to create awareness about accidental subdural injection during subarachnoid block. Anaesthesiologists should always keep in mind the possibility of subdural block in case of extensive sensory blockade following subarachnoid block to ensure timely management of its complications.

\section{References}

1. Agarwal D, Mohta M, Tyagi A, Sethi AK. Subdural block and the anaesthetist. Anaesth Intensive Care 2010;38(1):20-6. PMid:20191772

2. Caplan RA, Ward RJ, Posner K, Cheney FW. Unexpected cardiac arrest during spinal anaesthesia, 
a closed claims analysis of predisposing factors. Anesthesioloy.1988;68(1):5-11. http://dx.doi.org/10.1097/00000542-19880100000003

3. Mehta M, Maher R. Injection into extra arachnoid subdural space. Anaesthesia 1977;32:760-6. http://dx.doi.org/10.1111/j.13652044.1977.tb10077.x

PMid:579075

4. Collier CB. Accidental subdural block: four more cases and a radiographic review. Anaesth Intensive Care 1992;89:1267-8.

5. Chan YK, Gopinathan R, Rajendram R. Loss of consciousness following spinal anaesthesia for caesarean section. Br J Anaesth 2000;85(3):474-6. http://dx.doi.org/10.1093/bja/85.3.474 PMid:11103195

6. Stevens RA, Stanton-Hicks MA. Subdural injection of local anaesthetic: a complication of epidural anaesthesia. Anesthesiology 1985;63:323-6. http://dx.doi.org/10.1097/00000542-198509000-

$\underline{00016}$

PMid:4025896
7. Fragneto RY, Fisher A. Mental status change and aphasia after labor analgesia with intrathecal sufentanil/bupivacaine.

AnesthAnalg.2000;90(5):1175-1176.

http://dx.doi.org/10.1097/00000539-200005000-

00033

8. Singh B, Sharma P. Subdural block complicating spinal anaesthesia. Anesth Analg.2002;94:10071009.

http://dx.doi.org/10.1097/00000539-200204000$\underline{00043}$

PMid:11916813 